\title{
Government Stability, Corruption, Investment Conditions and Private Investment in Côte d'Ivoire: The Autoregressive Distributed Lag (ARDL) Approach
}

\author{
Diabate Nahoussé \\ Department of Economics, Alassane Ouattara University, Bouaké, Côte d'Ivoire \\ Email: fnahousse@yahoo.fr
}

How to cite this paper: Nahoussé, D. (2019) Government Stability, Corruption, Investment Conditions and Private Investment in Côte d'Ivoire: The Autoregressive Distributed Lag (ARDL) Approach. Modern Economy, 10, 1812-1828. https://doi.org/10.4236/me.2019.107117

Received: June 13, 2019

Accepted: July 22, 2019

Published: July 25, 2019

Copyright () 2019 by author(s) and Scientific Research Publishing Inc. This work is licensed under the Creative Commons Attribution International License (CC BY 4.0).

http://creativecommons.org/licenses/by/4.0/

\begin{abstract}
This study highlights the role of institutional factors in determining private investment in Côte d'Ivoire. The data come from the World Bank and the "Political Risk Services Group". The Autoregressive Distributed Lag (ARDL) approach was used. The reduction of investment risks, the fight against corruption and the preservation of governmental stability are determining factors of private investment in Côte d'Ivoire. It is recommended to establish a national authority with exceptional sanctioning powers to fight corruption more effectively and to promote a democratic culture that ensures a better quality of the institutional environment.
\end{abstract}

\section{Keywords}

Government Stability, Corruption, Investment Condition, Private and Public Investment

\section{Introduction}

Private investment has positive effects on economic growth [1] and on employment [2]. In addition, recent global financial crises have forced policy and economic decision-makers to look for alternative approaches to achieving sustainable growth. Thus, the development of private investment has been integrated as a solution [3].

With regard to Côte d'Ivoire, despite all the reforms that have been adopted, the potential inherent in private investment has not been well exploited. That's what motivates our study. Indeed, available statistics show that the ratio of pri- 
vate investment to GDP in Côte d'Ivoire is unsatisfactory (16.01\% of GDP $)^{1}$. Thus, deepen the reflections on the determinants of private investment in Côte d'Ivoire is essential. This could help to understand how private investment is stimulated in the country, and thus offer an empirical guide for policy formulation.

The behavior of the investment is a controversial issue in the literature. Since the pioneering work of Keynes [4], several studies on the determinants of investment have been carried out. They concern the approaches of Tobin's $q$ [5] and the accelerator [6] [7]. But, from the theories or approaches above, that of the flexible accelerator is the most popular and the most applied to analyze the behavior of investment in the least developed countries and especially in subSaharan Africa. For this reason, studies of private investment behavior in subSaharan Africa focus simply on the hypothesis tests that explain the variations in private investment in these economies [8].

Several studies on the determinants of private investment have been made in the developing world. This is the case of Waheed [9] in Pakistan, Nainggolan et al. [10] in Indonesia, Ambaye et al., 2014 [11] in Ethiopia, Hamuda et al. [12] in Tunisia, Molapo and Damane [13] in Lesotho, Ajide and Lawanson [3] in Nigeria.

Although the literature on investment is broad in both developed and developing countries, there are not many studies on the experiences of specific countries, especially for countries in the sub-Saharan region. For example, in Côte d'Ivoire, Diabaté [14] and Ouattara [15] conducted studies on the determinants of private investment. In his study, Diabaté [14] attempts to model the long-term determinants of domestic private investment in Côte d'Ivoire. The ARDL econometric technique is used. Data from the study cover the period from 1970 to 2012. The results indicate that public investment, foreign direct investment, trade are the main determinants of domestic short-term and long-term private investment in Côte d'Ivoire while the real GDP growth rate interest are statistically insignificant. Thus, efforts should be geared towards developing the necessary public investments in infrastructure such as constant electricity supply, good highways and the elimination of the negative effects of external shocks caused by uncertainty of investment on infrastructure and the deterioration of the terms of trade. Ouattara [14] analyzes the impact of corruption on public and private investments in Côte d'Ivoire and their effects on economic growth. Using data from the World Development Indicators (WDI) and Transparency International (TI) from 1998 to 2013, it shows empirically that corruption is a factor in overestimating the amount of investment in Côte d'Ivoire. His study then recommends a greater awareness of political and economic actors of the misdeeds of corruption and unconstitutional changes. It also suggests the establishment of a national authority with exceptional powers of sanction to better fight against corruption in all its forms.

Nevertheless, all of these studies are deficient in that they ignore certain key ${ }^{1}$ World Bank. 
determinants. Indeed, based on the work of Keho [16], the investment conditions and government stability are also determining variables to better understand the behavior of investment in general. These indicators are therefore elements to better understand the quality of the business environment. This study thus contributes to show that the institutional environment through investment conditions, corruption and the stability of the government can better explain the behavior of private investment in Côte d'Ivoire. Thus, this work provides the authorities with an additional tool for decision support.

To achieve these goals, our thinking revolves around three essential sections. Section 2 presents the macroeconomic environment and the literature review. Section 3 describes the methodology used. Section 4 presents the data, the empirical results and their economic interpretation. Section 5 presents the conclusion and then the implications of economic policies that flow from it.

\section{Macroeconomic Environment and Literature Review}

This section presents the macroeconomic environment in which private investment in Côte d'Ivoire is evolving as well as the theoretical and empirical determinants of investment.

\subsection{Overview of the Macroeconomic Environment in Côte d'Ivoire}

According to the "Doing Business" ranking 2014, the business environment in Côte d'Ivoire has improved a lot over the last two years, thanks in particular to the introduction of: a new investment code, a commercial court, a framework for dialogue with the private sector and a one-stop shop for starting a business. The country has thus joined the club of the 10 most dynamic African countries in terms of reform, allowing it to win ten places in the ranking to rank 167th out of 189 countries listed in 2013. Côte d'Ivoire is launching a dynamic of attracting international investors, through the aforementioned reforms as well as various events promoting the image of the country. The most outstanding so far are the donor advisory group held in late 2012 and the investing forum earlier this year. These actions are beginning to bear fruit, as attested by the mobilization of new investors such as Mauritius and Morocco.

In addition, fiscal policy over the 2016-2020 period is essentially focused on pursuing tax reforms and current collection systems in line with the objectives of the National Development Program (NDP) 2016-2020. The tax burden would increase from $15.5 \%$ in 2015 to $16.9 \%$ in 2020 in relation to the positive effects of the measures envisaged. These reforms will allow the government to mobilize significant own resources to finance part of its development program.

The Government will implement a series of large-scale reforms contained in the 2016-2020 NDP to achieve the goal of strong, sustained, inclusive, job-creating, gender and environmental growth. This package of measures includes: 1) maintaining the stability of the macroeconomic framework; 2) accelerating the improvement of the business climate, in particular the fight against corruption and 
the promotion of good governance; 3) the publication and exploitation of the results of the work of the Reform Commission whose mission is to propose corrective measures to overcome the shortcomings of the tax system for a better competitiveness of ivorian economy; 4) the continuation of the reform of the tax administration, the revision of the exemptions, the broadening of the tax base to small and medium-sized enterprises, the gradual taxation of the informal sector; 5) the establishment of a unique business identifier; 6) the completion of the implementation of the Single Treasury Account (TSA) for better management of the State treasury; 7) strengthening the traceability of Foreign Direct Investment flows; 8) the beginning of georeferencing of fixed assets and natural resources of the country; 9) the operationalization of the credit information bureau, and 10) the establishment of market values from the reliability of land management.

With respect to public debt management, it is important that public investment and other government funding continue to be provided under the Medium-Term Debt Management Strategy (MTDS). This strategy, consistent with the Debt Sustainability Analysis (DSA), ensures the control of costs and risks related to new financing. Indeed, the Strategy is gradually giving priority to domestic financing/resources and is careful to limit the foreign exchange risk associated with external borrowing.

To this end, the Government plans to mobilize more domestic resources over the medium and long term to meet its financing needs. In accordance with the 2016-2020 MTM, new funding is expected to be raised on average by $56 \%$ in the domestic market and $44 \%$ externally.

The massive flows of new financing (CFA 30,000 billion, of which about $\$ 11,284$ billion for the public sector) necessary for the implementation of the 2016-2020 NDP should be sought in a context of limited supply of concessional financing from conventional external creditors (multilateral and bilateral), thus the Government will continue to diversify its sources of financing, particularly bilateral and regional. It will also have cautious use of non-traditional financing and international financial markets while ensuring the sustainability of external debt.

Over the 2016-2020 periods, external financing represents $44 \%$ and consists of $20 \%$ non-concessional, 15\% semi-concessional and 9\% concessional. Domestic financing has a $56 \%$ share and consists of $6 \%$ short-term, $17 \%$ medium-term and $33 \%$ long-term.

\subsection{Theoretical Determinants of Investment}

The theoretical approach will focus on neoclassical and Keynesian analysis before explaining the investment theory from the perspective of flows, which is the model of Jorgenson [7]. Then follow some empirical work in developed and developing countries.

Since the pioneering work of Keynes [4], several studies on the determinants of investment starting with Tobin's accelerator, profit, neo-classical and $q$ ap- 
proaches have taken place [17] [18]. The flexible accelerator model suggested by Treadway [6], Lucas [19] and Goodwin [20] to address the shortcomings of the simple accelerator model. This model assumes that capital adjusts to its desired level in a constant proportion of the difference between the desired capital $\left(K^{*}\right)$ and its actual level $(K)$. The main lesson of this model is that the greater the gap between the existing capital stock and the desired capital stock, the higher the investment rate of a firm. The model is expressed as: $I=\varphi\left(K^{*}-K_{-1}\right)$ where $I$ is the net investment, $K^{*}$ the desired capital stock and $K_{-1}$ the capital stock of the previous period and $\varphi=$ the partial adjustment factor. Another version of the accelerator theory is the neo-classical approach to placement that was formulated by Jorgensen [7]. In his presentation, he stated that the desired capital stock is proportional to the firm's products and the cost of capital use which in turn depends on the price of capital goods, the real interest rate of depreciation and tax structure. As part of the investment profit approach, investment decisions are based on the profits made by the firm. Profit is the key determinant in facilitating investment financing both internally and externally.

According to the neo-classical investment model, investment decisions should be based on expected revenues and the cost of capital. In addition, Tobin's $q$ model shows that investment decisions are made if the replacement costs of physical assets are lower than the increase in the value of firm shares. Tobin argues that the level of business investment depends on the ratio of the present value of capital invested to the cost of replacing capital. He calls this report $q$. The theory of $q$ of investment assumes that firms want to increase their capital when $q>1$ and decrease their capital stock when $q<1$. But, Berndt [21] noted that in actual practice, the model is facing problems.

From the above theories or approaches, flexible accelerator theory is the most popular and applied one to analyze investment behavior as it can easily be applied to least developed countries. This is because data on key variables such as capital stock and depreciation rates are not readily available for most of these countries and in particular for sub-Saharan African countries. For this question, studies on private investment behavior in sub-Saharan Africa simply focus on hypothesis testing that explains the variations in private investment in these economies [8].

\subsection{Empirical Studies on the Determinants of Private Investment}

Waheed [9] analyzes the determinants of domestic private investment in Pakistan using time series covering the period 1982 to 2012 . His study shows that the long-run determinants are the interest rate, the public investment, FDI, the exchange rate, the external debt ratio and the political regime. Nainggolan et al. [10] analyze the determinants of private investment in North Sumatra Province of Indonesia. The observed variables are regional gross domestic product (GDP), public investment, interest rate, exchange rate, credit to the private sector, inflation, international interest rate and a DUMY variable that takes into account the 
effect of the economic crisis during the period 1980-2011. Through an Error Correction Model (ECM), the authors showed that in the short and long run, GDP, exchange rate and credit to the private sector have a positive and significant effect on private investment, while that public investment, interest rates, inflation and the economic crisis have a significant but negative effect on private investment. Meanwhile, the international interest rate (LIBOR) has a negative and negligible effect on private investment in North Sumatra. Molapo and Damane [13] find in Lesotho that private investment is influenced by the level of economic growth, public investment, price level, public investment and macroeconomic instability. Ambaye et al. [11] examine the determinants of domestic private investment in Ethiopia using time series covering the period 1992-2010. They use an autoregressive pattern with staggered delays (ARDL). The study shows that the exchange rate, domestic savings and domestic credit are key factors with negative and significant effects on domestic private investment. External debt and public spending are found to have significant and positive effects on domestic private investment. Eshun et al. [22] obtained in the case of Ghana that the decline in private investment, both short-term and long-term is linked to high real interest rates. Hamuda et al. [12] examines the determinants of domestic investment in Tunisia using annual data for the period 1961-2011. An autoregressive pattern with staggered delays (ARDL) is used. Their results show that there is an equilibrium relationship between investment and the monetary base. Ajide and Lawanson [3] model the long-term determinants of domestic private investment in Nigeria over the period 1970-2010, using the Autoregressive Lag Delay (ARDL) technique. They get that public investment, real GDP, real interest rate, exchange rate, credit to the private sector, terms of trade, external debts and dummy reforms are long-term factors of the domestic private investment while public investment, real GDP and terms of trade are statistically significant in the short term.

Reviewing the theoretical and empirical analyzes, we will now discuss in Section 3 of our study, the methodological approach.

\section{Methodological Approach}

Our approach is to first specify the model of our study that will allow us to analyze the impact of political factors on growth. Then we will expose the estimation method used to estimate the specified model.

\subsection{Specification of the Model}

By modeling the determinants of investment, five approaches are generally considered. These main areas of investment behavior include the simple accelerator model, liquidity theory, expected profit theory, Tobin's $q$ theory, and neoclassical flexible accelerator theory. The flexible accelerator model seems to be the most popular of these theories used in empirical studies. However, in the context of developing countries, due to data limitations and structural constraints, a variant 
of the flexible accelerator model has often been used in empirical research, including the literature on the determinants of private investment in these countries. The neoclassical investment theory suggests that private investment is positively related to real GDP growth [22] [23].

Similarly, it has also been hypothesized that private investment is positively influenced by income level, as countries with higher income levels would tend to devote more of their wealth to national saving than would then be used to finance the investment [24].

Investment in the public sector has also been suggested to affect private investment, although its impact remains ambiguous. Public investment can stimulate private investment by increasing private returns through the provision of infrastructure (communication, transport, energy, etc.). Studies such as Greene and Villanueva [24], Aschauer [25] and Blejar and Khan [26] have shown complementarity between public and private savings. Conversely, public investment can crowd out private investment if the additional investment is financed by a deficit, leading to an increase in interest rates, credit rationing and a tax burden. Empirical studies by Rossiter [27] and Chhiber and Wijnbergen [28] report a negative effect of public investment on private investment.

The effect of credit to the private sector on private investment should be positive. Private firms in developing countries rely heavily on bank credit as a source of finance. As financial markets are generally repressed, credit policies generally affect private sector investments through the outstanding credit available to companies with access to preferential interest rates. Empirically, although the vast majority of studies seem to confirm the positive impact of increased private sector credit on private investment, there are cases where these credits do not seem to have any effect. For example, Oshikoya [29] found that increased credit to the private sector was not associated with increased private investment in Morocco, Tanzania and Zimbabwe.

In the context of developing countries, the flexible accelerator model can be adjusted to take into account foreign aid flows. Foreign aid flows can increase sectoral investment through the conditionality attached to them. A condition attached to these flows since the 1980s is that the recipient country must privatize some state-owned enterprises. Aid can also increase private investment if donors use it to provide private credit through local institutions and non-governmental organizations. Finally, aid flows tend to be associated with tax cuts in recipient countries. If this reduction is targeted at the private sector, it could boost its investment.

Finally, the terms of trade appear to be another important determinant of investment in developing countries. This variable is often used to impute external shocks to the economy. Negative terms of trade imply that more export units are needed per unit of imports. This could aggravate the current account deficit, which is an indicator of macroeconomic instability, and have a negative effect on private investment. If the deterioration of the terms of trade is generated by an 
increase in the price of imports, this would tend to increase the consumer price index. If this is the effect of a reduction in export prices, export earnings will decrease, which will reduce investment in this sector.

In addition, based on the work of Keho [16], investment conditions assess the factors that affect investment risks. This indicator takes into account the viability of contracts with the State and the risk of expropriation of private assets, the repatriation of profits and late payments of supplier credits. The corruption indicator measures the extent of corruption and the way in which public power is exercised for private purposes. Finally, the stability of government measures the ability of governments to deliver the programs they have planned and to stay in place. Keeping in mind the discussion above, and the study of Diabate [14], the equation of our private investment model is assumed to take the following representation:

$$
\text { prinv }_{t}=F\left(\text { invcond }_{t}, \text { stabgov }_{t}, \text { corr }_{t}, \text { pubinv }_{t}, \text { trade }_{t}, \text { growth }_{t}\right)
$$

where prinv $=$ the private investment rate, invcond $=$ the investment conditions, stabgov $=$ the government stability, corr $=$ the corruption indicator, pubinv $=$ the public investment rate, trade $=$ the ratio of the value of trade to GDP and growth $=$ the real GDP growth rate.

\subsection{Estimation Method}

In this study, the ARDL approach developed by Pesaran et al. [30] is adopted. But this approach requires that the order of series integration be checked first. Indeed, this procedure is not applicable when a series is integrated of higher order than one [31]. Thus, model variables can be zero order, I (0), or integrated order one, I (1), or can be I (0) and I (1).

The use of the Wald test or the F-statistic makes it possible to test the significance of the delay of the variables by taking into account the constraint of an error correction model (ECM). The asymptotic distribution of this test (Fisher's respectively) is non-standardized under the null hypothesis of no cointegration between the variables. Therefore, the calculated value of this statistic must, to validate or invalidate one of the hypotheses, be compared to the critical values established by the procedure of Pesaran et al. [30].

It is important to note that critical values based on large samples differ significantly from those of small size. Narayan [32] reports small critical values of the sample. The critical values of the upper bound are estimated assuming that all variables of the ARDL model are integrated by order one [I (1)], and the lower bound critical values are computed assuming the variables are built-in order zero [I (0)]. At any chosen level of significance, if the calculated F-statistic is between the lower and upper critical values, the decision on cointegration between the underlying variables is inconclusive.

However, if the calculated F-statistic exceeds the critical value of the upper limit, the null hypothesis is rejected and the decision is that the underlying variables are cointegrated. On the other hand, if the calculated F-statistic is less 
than the critical value of the lower limit, the null hypothesis is not rejected and it is concluded that the variables are not cointegrated.

The long-run equilibrium relationship between private investment and its determinants (the variables that better capture the behavior of domestic private investment such as Keynesian, neoclassical, neo-liberal and uncertainty variables) can be expressed as following:

$$
\begin{aligned}
\text { prinv }_{t}= & \theta_{0}+\theta_{1} \text { invcond }_{t}+\theta_{2} \text { stabgov }_{t}+\theta_{3} \text { corr }_{t}+\theta_{4} \text { pubinv }_{t} \\
& +\theta_{5} \text { trade }_{t}+\theta_{6} \text { growth }_{t}+\varepsilon_{t}
\end{aligned}
$$

where: prinv $=$ the private investment rate; invcond : the investment conditions; stabgov: the government stability; corr : the indicator of corruption; pubinv : public investment rate; growth: GDP growth rate; trade: the ratio of the value of trade to GDP. Indeed, we adopt the model developed by Ajide and Lawanson $[3]^{2}$.

Our ARDL model then looks like this:

$$
\begin{aligned}
& \Delta \operatorname{prinv}_{t}=\beta_{0}+\sum_{i=1}^{p} \beta_{1 i} \Delta_{\text {invcond }}+i+\sum_{i=0}^{n} \beta_{2 i} \Delta \text { stabgov }_{t-i}+\sum_{i=0}^{n} \beta_{3 i} \Delta \operatorname{corr}_{t-i}
\end{aligned}
$$

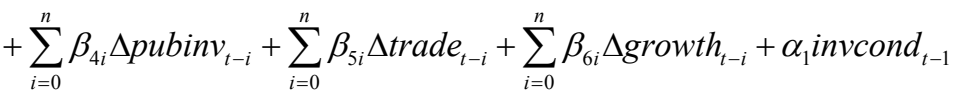

$$
\begin{aligned}
& +\alpha_{2} \text { stabgov }_{t-1}+\alpha_{3} \text { corr }_{t-1}+\alpha_{4} \text { pubinv }_{t-1}+\alpha_{5} \text { trade }_{t-1}+\alpha_{6} \text { growth }_{t-1}+\varepsilon_{t}
\end{aligned}
$$

In this equation, $\Delta$ denotes the first difference operator, $\varepsilon_{t}$ represents the error term which is a white noise, $n$ is the optimal delay, and $\beta_{0}$ is the constant. The parameters that go $\alpha_{1}$ from to $\alpha_{6}$ characterize the long-run equilibrium between the variables while the coefficients $\beta_{1}$ to $\beta_{6}$ represent the short-run equilibrium between the series studied. The delay $p$ is determined by the information criteria AIC and SC, it corresponds to the delay which minimizes these criteria. To test the absence of cointegration, Pesaran et al. [30] proceeded to the following test: $H_{0}=\alpha_{1}=\alpha_{2}=\alpha_{3}=\alpha_{4}=\alpha_{5}=\alpha_{6}=0$ (Absence of cointegration); against the alternative hypothesis $H_{1}$ : (Presence of cointegration) using the Fisher (or Wald) tests according to a non-standard law [33].

If there is cointegration, we develop an error correction model (ECM) as follows:

$$
\begin{aligned}
\text { sprinv }_{t}= & \beta_{0}+\sum_{i=1}^{p} \beta_{1 i} \text { sinvcond }_{t-i}+\sum_{i=0}^{n} \beta_{2 i} \text { stabgov }_{t-i}+\sum_{i=0}^{n} \beta_{3 i} \text { scorr }_{t-i} \\
& +\sum_{i=0}^{n} \beta_{4 i} \Delta \text { pubinv }_{t-i}+\sum_{i=0}^{n} \beta_{5 i} \text { strade }_{t-i}+\sum_{i=0}^{n} \beta_{6 i} \text { sgrowth }_{t-i}+\lambda e c+\varepsilon_{t}
\end{aligned}
$$

where $\lambda$ is the rate of adjustment of the parameter and $e c$ represents the residuals obtained from the estimate of the equation of the cointegrated model.

What about the accuracy of study variables and data sources?

${ }^{2}$ Since WAEMU countries follow a common monetary policy, nominal interest rates are the same and therefore real interest rates are correlated with the rate of inflation. Indeed, inflation reduces the real interest rate, which has negative effects on credit volume, level of investment and economic activity [34]. That's why we do not take into account the inflation rate and the credit rate to the private sector. 


\section{Presentation of Data and Empirical Results}

We strive to present and analyze the study data before proceeding with an econometric implementation and then interpreting the results.

\subsection{Presentation of the Data}

The study uses annual data covering the period from 1984 to 2013 on Côte d'Ivoire. The choice of this period is linked to the availability of data on the variables of this period. Trade data (trade), gross domestic product growth rate ( growth), public investment ( pubinv) and private investment ( prinv) are collected from World Development Indicators ${ }^{3}$ (WDI) database of the World Bank. All these variables are expressed in rates. Moreover, following the work of Diabate [14], we retain three other indicators of private investment: investment conditions, corruption and the stability of the government. In addition, based on the work of Keho [16], the investment conditions (invcond) assess the factors that affect investment risks. This indicator takes into account the viability of contracts with the State and the risk of expropriation of private assets, the repatriation of profits and late payments of supplier credits. The corruption indicator (corr ) measures the extent of corruption and the manner in which public power is exercised for private purposes. Finally, the government stability ( stabgov) measures the ability of governments to deliver the programs they have planned and to stay in place. These indicators are scored on varying scales with a high score indicating a better quality of the business environment. They come from the database of the International Country Risk Guide 4 produced by the Political Risk Service Group (PRS Group ${ }^{5}$ ). Regardless of the methodological and statistical reservations that can be made against these indicators, they are taken seriously by foreign investors and advisory bodies. The main advantage of these data compared to other indicators lies in their availability over a relatively longer period (1984-2013) to analyze the dynamics of the variables and their influences on private investment. To facilitate the analysis, the variables have been transformed so that they take values between 0 and 10. A high score indicates better institutional quality [16] and therefore a more attractive environment for investors.

We present the averages by sub-periods of these variables. The evolution of the indicators shows some progress over time, with the exception of the control of corruption and the indicator of investment conditions. Corruption has increased since 1990. The investment conditions indicator has also deteriorated since 1999. The deterioration of the macroeconomic framework since 1999 is

${ }^{3}$ These data were collected on the following website:

http://datatopics.worldbank.org/world-development-indicators/

${ }^{4}$ The International Country Risk Guide (ICRG) was created in 1980 by the International Report editors for more than 120 countries and includes 22 indexes. In 1992 they joined the PRS Group (Political Risk Services).

${ }^{5}$ These data were collected on the following website:

https://www.prsgroup.com/tag/2018-political-risk-index/ 
linked to the context of socio-political turmoil in the country since 1999. From 2012, the business environment in this country is improving. Another highlight of this data is the extent and persistence of corruption in Côte d'Ivoire. These results also show a stagnation of the private investment rate over the entire period of the study, with the exception of the period 1990-1994 when there is a significant decrease (see Table 1).

It is therefore reasonable to try to understand the reasons for this situation. How do these indicator variables affect the level of private investment in Côte d'Ivoire?

\subsection{Empirical Results}

Several tests are needed to test the assumptions under which model estimation can be efficient. The tests we present are the cointegration test and the diagnostic tests.

\subsubsection{Stationarity Tests}

Before any analysis, it is imperative to check the degree of stationarity of each time series. Commonly used methods are the Augmented Dickey-Fuller (ADF) and Kwiatkowski, Phillips, Schmidt and Shin (KPSS) tests ${ }^{6}$ (see Table 2).

The results presented in Table 3 show that the maximum order of integration of the variables is an I (1). Therefore, the cointegration test is applicable to the data.

\subsubsection{Cointegration Test}

The next step is to perform the cointegration test. It appears that the variables of pubinv, growth, trade, corr, invcond, stabgov can be considered as slightly exogenous for the long-term coefficients at the 5\% level. The only long-run relationship is one that identifies the private investment rate as the variable explained ( prinv). Indeed, the calculated F-statistic $(10,258)$ is greater than the critical value greater than $1 \%, 5 \%$ and $10 \%$ (see Table 3 ).

Table 1. Evolutions of the few indicators and the rate of private investment in Côte d'Ivoire.

\begin{tabular}{cccccccc}
\hline Variables & Symbols & $\mathbf{8 4 - 8 9}$ & $\mathbf{9 0 - 9 4}$ & $\mathbf{9 5 - 9 9}$ & $\mathbf{0 0 - 0 4}$ & $\mathbf{0 5}-\mathbf{0 9}$ & $\mathbf{1 0}-\mathbf{1 3}$ \\
\hline Investment conditions & invcond & 5.36 & 5.15 & 5.38 & 4.38 & 4.90 & 7.50 \\
Corruption indicator & corr & 4.79 & 5.31 & 4.19 & 3.53 & 5.00 & 4.44 \\
Government Stability & stabgov & 4.07 & 5.15 & 7.06 & 7.19 & 7.25 & 8.23 \\
Public investment & pubinv & 3.68 & 3.97 & 4.94 & 5.08 & 6.26 & 7.19 \\
Trade & trade & 68.08 & 60.21 & 76.17 & 77.56 & 91.30 & 90.71 \\
GDP growth & growth & 3.18 & 0.88 & 4.55 & 4.20 & 3.83 & 3.43 \\
Private investment & prinv & 7.32 & 5.64 & 8.71 & 6.81 & 7.47 & 7.26 \\
\hline
\end{tabular}

Source: Author's calculation from WDI and PRS Group data.

${ }^{6}$ For details, see Diabaté [14]. 
Table 2. Unit root tests results.

\begin{tabular}{|c|c|c|c|c|c|c|}
\hline & \multicolumn{3}{|c|}{ Inlevel } & \multicolumn{3}{|c|}{ In first differences } \\
\hline & $\mathrm{ADF}$ & PP & KPSS & $\mathrm{ADF}$ & PP & KPSS \\
\hline \multirow[t]{2}{*}{ Private investment } & -2.305 & -2.174 & $0.760^{*}$ & $-7.541^{\star}$ & $-8.413^{*}$ & 0.111 \\
\hline & $(-2.930)$ & $(-2.930)$ & $(0.463)$ & $(-2.931)$ & $(-2.931)$ & $(0.463)$ \\
\hline \multirow[t]{2}{*}{ Trade } & $-3.380^{\star}$ & $-3.380^{*}$ & $0.159^{*}$ & $-7.907^{\star}$ & $-8.413^{\star}$ & 0.111 \\
\hline & $(-2.930)$ & $(-2.930)$ & $(0.463)$ & $(-2.931)$ & $(-2.931)$ & $(0.463)$ \\
\hline \multirow[t]{2}{*}{ Public investment } & -2.035 & -2.338 & 0.790 & $-8.586^{\star}$ & $-28.302^{*}$ & 0.243 \\
\hline & $(-2.931)$ & $(-2.930)$ & $(0.463)$ & $(-2.933)$ & $(-2.931)$ & $(0.463)$ \\
\hline \multirow[t]{2}{*}{ Growth } & $-8.599^{*}$ & $-8.749^{\star}$ & $0.291^{*}$ & $-6.190^{*}$ & $-52.163^{\star}$ & 0.148 \\
\hline & $(-2.930)$ & $(-2.930)$ & $(0.463)$ & $(-2.939)$ & $(-2.931)$ & $(0.463)$ \\
\hline \multirow[t]{2}{*}{ Investment conditions } & $-2.951^{\star}$ & $-3.768^{\star}$ & 0.570 & $-11.529^{*}$ & $-15.541^{*}$ & 0.070 \\
\hline & $(-2.931)$ & $(-2.930)$ & $(0.463)$ & $(-2.931)$ & $(-2.931)$ & $(0.463)$ \\
\hline \multirow[t]{2}{*}{ Corruption } & -2.039 & -2.339 & 0.763 & $-8.586^{\star}$ & $-28.302^{*}$ & 0.243 \\
\hline & $(-2.940)$ & $(-2.927)$ & $(0.463)$ & $(-2.933)$ & $(-2.931)$ & $(0.463)$ \\
\hline \multirow[t]{2}{*}{ Government stability } & $-5.993^{*}$ & $-3.380^{*}$ & $0.159^{*}$ & $-7.931^{*}$ & $-8.412^{*}$ & 0.111 \\
\hline & $(-2.930)$ & $(-2.930)$ & $(0.463)$ & $(-2.740)$ & $(-2.740)$ & $(0.463)$ \\
\hline
\end{tabular}

Source: Author's estimate based on data from WDI and PRS Group. Note:*indicate significant at the $5 \%$.

Table 3. Results of the cointegration test.

\begin{tabular}{|c|c|c|c|c|c|c|c|c|}
\hline \multirow{2}{*}{$\begin{array}{c}\text { Variable } \\
\text { dépendante }\end{array}$} & \multirow{2}{*}{ F-Statistic } & \multicolumn{2}{|c|}{ CV à $10 \%(K=6)$} & \multicolumn{2}{|c|}{ CV à $5 \%(K=6)$} & \multicolumn{2}{|c|}{ CV à $1 \%(K=6)$} & \multirow{2}{*}{ Remarks } \\
\hline & & $\mathrm{I}(0)$ & $\mathrm{I}(1)$ & $\mathrm{I}(0)$ & $\mathrm{I}(1)$ & $\mathrm{I}(0)$ & $\mathrm{I}(1)$ & \\
\hline \multirow{2}{*}{ prinv } & \multirow{2}{*}{10.258} & $\mathrm{~T} 1=2.306$ & $\mathrm{~T} 1=3.353$ & $\mathrm{~T} 1=2.734$ & $\mathrm{~T} 1=3.920$ & $\mathrm{~T} 1=3.657$ & $\mathrm{~T} 1=3.674$ & \multirow{2}{*}{ Yes } \\
\hline & & $\mathrm{T} 2=2.276$ & $\mathrm{~T} 2=3.297$ & $\mathrm{~T} 2=2.694$ & $\mathrm{~T} 2=3.829$ & $\mathrm{~T} 2=5.256$ & $\mathrm{~T} 2=5.019$ & \\
\hline \multirow{2}{*}{ trade } & \multirow{2}{*}{-2.568} & $\mathrm{~T} 1=2.306$ & $\mathrm{~T} 1=3.353$ & $\mathrm{~T} 1=2.734$ & $\mathrm{~T} 1=3.920$ & $\mathrm{~T} 1=3.657$ & $\mathrm{~T} 1=3.674$ & \multirow{2}{*}{ No } \\
\hline & & $\mathrm{T} 2=2.276$ & $\mathrm{~T} 2=3.297$ & $\mathrm{~T} 2=2.694$ & $\mathrm{~T} 2=3.829$ & $\mathrm{~T} 2=5.256$ & $\mathrm{~T} 2=5.019$ & \\
\hline \multirow{2}{*}{ pubinv } & \multirow{2}{*}{-2.423} & $\mathrm{~T} 1=2.306$ & $\mathrm{~T} 1=3.353$ & $\mathrm{~T} 1=2.734$ & $\mathrm{~T} 1=3.920$ & $\mathrm{~T} 1=3.657$ & $\mathrm{~T} 1=3.674$ & \multirow{2}{*}{ No } \\
\hline & & $\mathrm{T} 2=2.276$ & $\mathrm{~T} 2=3.297$ & $\mathrm{~T} 2=2.694$ & $\mathrm{~T} 2=3.829$ & $\mathrm{~T} 2=5.256$ & $\mathrm{~T} 2=5.019$ & \\
\hline \multirow{2}{*}{ growth } & \multirow{2}{*}{-2.125} & $\mathrm{~T} 1=2.306$ & $\mathrm{~T} 1=3.353$ & $\mathrm{~T} 1=2.734$ & $\mathrm{~T} 1=3.920$ & $\mathrm{~T} 1=3.657$ & $\mathrm{~T} 1=3.674$ & \multirow{2}{*}{ No } \\
\hline & & $\mathrm{T} 2=2.276$ & $\mathrm{~T} 2=3.297$ & $\mathrm{~T} 2=2.694$ & $\mathrm{~T} 2=3.829$ & $\mathrm{~T} 2=5.256$ & $\mathrm{~T} 2=5.019$ & \\
\hline \multirow{2}{*}{ invcond } & \multirow{2}{*}{1.846} & $\mathrm{~T} 1=2.306$ & $\mathrm{~T} 1=3.353$ & $\mathrm{~T} 1=2.734$ & $\mathrm{~T} 1=3.920$ & $\mathrm{~T} 1=3.657$ & $\mathrm{~T} 1=3.674$ & \multirow{2}{*}{ No } \\
\hline & & $\mathrm{T} 2=2.276$ & $\mathrm{~T} 2=3.297$ & $\mathrm{~T} 2=2.694$ & $\mathrm{~T} 2=3.829$ & $\mathrm{~T} 2=5.256$ & $\mathrm{~T} 2=5.019$ & \\
\hline \multirow{2}{*}{ corr } & \multirow{2}{*}{3.014} & $\mathrm{~T} 1=2.306$ & $\mathrm{~T} 1=3.353$ & $\mathrm{~T} 1=2.734$ & $\mathrm{~T} 1=3.920$ & $\mathrm{~T} 1=3.657$ & $\mathrm{~T} 1=3.674$ & \multirow{2}{*}{ No } \\
\hline & & $\mathrm{T} 2=2.276$ & $\mathrm{~T} 2=3.297$ & $\mathrm{~T} 2=2.694$ & $\mathrm{~T} 2=3.829$ & $\mathrm{~T} 2=5.256$ & $\mathrm{~T} 2=5.019$ & \\
\hline \multirow{2}{*}{ stabgov } & \multirow{2}{*}{ 1. 829} & $\mathrm{~T} 1=2.306$ & $\mathrm{~T} 1=3.353$ & $\mathrm{~T} 1=2.734$ & $\mathrm{~T} 1=3.920$ & $\mathrm{~T} 1=3.657$ & $\mathrm{~T} 1=3.674$ & \multirow{2}{*}{ No } \\
\hline & & $\mathrm{T} 2=2.276$ & $\mathrm{~T} 2=3.297$ & $\mathrm{~T} 2=2.694$ & $\mathrm{~T} 2=3.829$ & $\mathrm{~T} 2=5.256$ & $\mathrm{~T} 2=5.019$ & \\
\hline
\end{tabular}

Note: Critical values are taken from Narayan [2]; Case II: restricted interception and no trend, T1 $=40$ and T2 $=45$ respectively. Source: Author's estimate based on data from WDI and PRS Group.

After confirming the existence of a long-term relationship between the variables in the model, we estimate the long-term and short-run models of our model. 


\subsubsection{Empirical Estimation Results}

Our results show that in Côte d'Ivoire, private investment is well explained by the independent variables chosen, namely the index of corruption, public investment, investment conditions, stability of government and trade. Indeed, the results of the estimate give an adjusted $\mathrm{R}^{2}$ of 0.62 . Furthermore, the error-correction coefficient is negative $(-0.346)$, as required, and is very significant; which justifies the specification of our model (see Table 4 ).

It is now necessary to examine the relevance of our results through diagnostic tests.

\subsubsection{Residual Diagnostics Tests}

The tests performed for the validity of our model consist in testing the normality,

Table 4. Results of estimation of the impact of corruption, government stability andinvestment conditions on private investment in the ARDL model.

Dependent variable prinv

The Akaike Information Criterion (AIC) used to select the shift structure in the ARDL model $(1,3,4,3,2,3,4)$

Short Run Form

Independent variables

Constant

Corruption

Public investment

Growth

Investment conditions

Trade

Government stability

$\operatorname{ECM}(-1)$

Corruption

Public investment

Growth

Investment conditions

Trade

Government stability

Coefficients $^{7}$
0.031
-0.185
-0.243
0.023
0.380
0.332
0.254
-0.346

T-Statistic

Probability

\section{Long Run Form}

0.131

2.670

0.037

$-2.180$

$-3.264$

4.2900 .000

$-3.2420 .031$

$-3.1140 .039$

2.4630 .060

3.8310 .025

2.5560 .048

5.0450 .000

$-5.9730 .000$

0.000

0.512

2.563

0.821

3.831

0.041

1.061

2.382

0.000

0.602

3.204

0.047

0.602

2.976

0.000

0.001

0.026

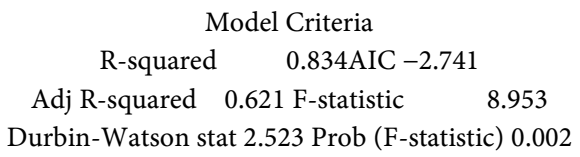

Source: Author's estimate based on data from WDI and PRS Group.

${ }^{7}$ These coefficients are elasticities. 
the heteroscedasticity, the absence of autocorrelation, the structural stability of the coefficients and the errors of specification. The results of the diagnostic tests show that model residuals satisfy all the assumptions of the linear model (see Table 5).

Public investments have a negative and significant impact on private investment $(-0.243)$ in the short term while in the long term they positively influence private investment in Côte d'Ivoire $(0.512)$ at $5 \%$. Public investment therefore has a ripple effect on private investment in Côte d'Ivoire, in the long term. Thus, even if the State is heavily involved in investment activities in this country, the basic infrastructure component (communication, transport, energy, health, education, etc.) has been dominant. Note that according to Blejer and Kahn [26], economic and social investment is complementary to private investment. This result is consistent with that of Greene and Villanueva [24] and Ajide and Lawanson [3].

Investment conditions have a positive and significant impact in the short term (0.380) and in the long term (1.061) on private investment at 5\% in Côte d'Ivoire. These results highlight that investors are less risky by investing in Côte d'Ivoire.

Trade, with coefficients of (0.332) and (0.602) respectively in the short and long term, reveals a positive impact on private investment in Côte d'Ivoire. Thus, trade improves the current account balance of Côte d'Ivoire. In addition, this result highlights the importance of economic openness and economic integration for ivorian economy. On the empirical level, this result is consistent with the work of Ajide [35] and Diabaté [14].

As for corruption, it negatively influences private investment flows in Côte d'Ivoire both in the short term $(-0.185)$ and in the long term $(-2.180)$. Indeed, the extent of corruption is often cited as the main factor affecting the volume of public and private investment. This result confirms the study by Ouattara [15] which highlights the perverse effect of corruption on the level of private investment in Côte d'Ivoire. Moreover, according to Kého [16], the control of corruption is an important determinant for the development of the financial sector and growth in WAEMU.

Government stability of has a positive effect on private investment in Côte d'Ivoire in the short term (0.254) and long term (0.001). This result shows that the stability of government is a prerequisite for the emergence of a more productive

Table 5. Results of residual diagnostics tests.

\begin{tabular}{ccc}
\hline Test & Chi2 & Prob > chi2 \\
\hline Normality Test & 0.701 & 0.398 \\
Heteroskedasticity (ARDL) & 0.301 & 0.591 \\
Breusch Godfrey LM test & 0.748 & 0.371 \\
Breusch-Pagan & 2.843 & 0.197 \\
Ramsey RESET & 0.495 & 0.703 \\
\hline
\end{tabular}

Source: Author's estimate based on data from WDI and PRS Group. 
level of investment. Empirically, our study supports the conclusions of the study by Kého [16] on the importance of maintaining a stable and peaceful political environment for the WAEMU economies, particularly for Côte d'Ivoire.

According to economic theory, the growth rate of GDP per capita does not affect the level of private domestic investment in the short term. In the long term, it positively and significantly influences the level of private domestic investment in Côte d'Ivoire at 5\%. On the theoretical level, the result confirms the accelerating effect of the neoclassical economic growth rate in Côte d'Ivoire. This result confirms those of Naa-Idar et al. [36] and Ramli et al. [10] and opposes those of Diabaté [14].

\section{Conclusions and Recommendations}

The main objective of this study was to highlight the role of institutional factors in the determination of private investment in Côte d'Ivoire. Indeed, recent global financial crises have led to a reduction in foreign direct investment (FDI) inflows and portfolio investment to developing countries, resulting in a renewed interest in modeling the determinants of private investment in Côte d'Ivoire. In order to reach the set objective, we used annual data covering the period 1970 to 2014. The Auto-Regressive Distributed Lag econometric technique (ARDL) was used. The results showed that public investment, trade development, investment risk reduction, control of corruption and the preservation of a stable political environment are major determinants of short and long term private investment in Côte d'Ivoire.

Thus, efforts should be directed towards the implementation of the necessary public investments (infrastructure such as constant electricity supply, good highways, best care delivery system, etc.) in order to provide an environment conducive to the development of private domestic investment, in particular ivorian small and medium-sized enterprises. Secondly, there needs to be a focus on reducing the negative effects of external shocks caused by investment uncertainty and terms of trade degradation. It also suggests, as in Ouattara [15], the establishment of a national authority with exceptional powers of sanction to better fight against corruption in all its forms. Finally, since the majority of variables are significant in the long term, it is important that polity programs can survive changes in government, hence the need to promote a democratic culture to ensure a stable and high quality institutional environment.

\section{Conflicts of Interest}

The author declares no conflicts of interest regarding the publication of this paper.

\section{References}

[1] Dehn, J. (2000) Private Investment in Developing Countries: The Effects of Commodity Shocks and Uncertainty. WPS, Oxford, 11. 
[2] Jayaraman, T.K. and Baljeet, S. (2007) Foreign Direct Investment and Employment Creation in Pacific Island Countries: An Empirical Study of Fiji. Asia-Pacific Research and Training Network on Trade Working Paper Series No. 35, 1-15.

[3] Ajide, K.B. and Lawanson, O. (2012) Modelling the Long Run Determinants of Domestic Private Investment in Nigeria. Asian Social Science, 8, 139-152. https://doi.org/10.5539/ass.v8n13p139

[4] Keynes, M.J. (1936) La théorie générale de l'emploi, l'intérêt et la monnaie. Jean-de Largentaye, Payot, Paris, IV, V, VI, 1-181.

[5] Tobin, J. (1969) A General Equilibrium Approach To monetary Theory. Journal of Money, Credit and Banking, 1, 15-29. https://doi.org/10.2307/1991374

[6] Treadway, B.A. (1974) The Globally Optimal Flexible Accelerator. Journal of Economic Theory, 7, 17-39. https://doi.org/10.1016/0022-0531(74)90078-7

[7] Jorgensen, D.W. (1971) Econometric Studies of Investment Behavior: A Survey. Journal of Economic Literature, 9, 1111-1147.

[8] Mutenyo, J., Asmah, E. and Kalio, A. (2010) Does Foreign Direct Investment Crowd-Out Domestic Private Investment in Sub-Saharan Africa? The African Finance Journal, 12, 27-51.

[9] A. Waheed, (2015) Determinants of Domestic Private Investment: Test of Alternative Hypotheses for Pakistan. International Journal of Research in Business and Social Science, 4, 35-43. https://doi.org/10.20525/ijrbs.v4i2.24

[10] Nainggolan, P., Ramli, R., Daulay, M. and Rujiman, R. (2014) An Analysis of Determinant on Private Investment in North Sumatra Province, Indonesia. Journal of Management Research, 7, 38-57. https://doi.org/10.5296/jmr.v7i1.6541

[11] Ambaye, G., Berhanu, T. and Abera, G. (2014) Modeling the Determinants of Domestic Private Investment in Ethiopia. Agris Online Papers in Economics and Informatics, 5, 13-23.

[12] Hamuda, A.M., Suliková, V., Gazda, V. and Horváth, D. (2013) ARDL Investment Model of Tunisia. Theoretical and Applied Economics, 20, 57-68.

[13] Molapo, S. and Damane, M. (2015) Determinants of Private Investment in Lesotho. European Scientific Journal, 11, 473-491.

[14] Diabaté, N. (2016) An Analysis of Long Run Determinants on Domestic Private Investment in Côte d'Ivoire. European Scientific Journal, 12, 240-251. https://doi.org/10.19044/esj.2016.v12n28p240

[15] Ouattara, W. (2011) Corruption, investissements et croissance économique en côte d'ivoire? Savings and Development, 35, 55-73. https://doi.org/10.2307/savideve.35.1.55

[16] Keho, Y. (2012) Le rôle des facteurs institutionnels dans le developpement financier et économique des pays de l'UEMOA. Revue Économique et Monétaire, 12, 9-43.

[17] Eisner, R. and Nadiri, M.I. (1968) Investment Behavior and Neo-Classical Theory. The Review of Economics and Statistics, 50, 369-382. https://doi.org/10.2307/1937931

[18] Seruvatu, E. and Jayaraman, T.K. (2001) Determinants of Private Investment in Fiji. Working Paper 2, Economics Department, Reserve Bank of Fiji, Suva.

[19] Lucas, E.R. (1967) Optimal Investment Policy and the Flexible Accelerator. International Economic Review, 8, 78-85. https://doi.org/10.2307/2525383

[20] Goodwin, R.M. (1951) The Nonlinear Accelerator and the Persistence of Business Cycles. Econometrica, 19, 1-17. https://doi.org/10.2307/1907905 
[21] Berndt, E. (1990) The Practice of Econometrics: Classic and Contemporary. MIT, Reading.

[22] Eshun, M.E., Adu, G. and Buabeng, E. (2014) The Financial Determinants of Private Investment in Ghana. MPRA Paper 57570.

[23] Fielding, D. (1997) Adjustment, Trade Policy and Investment Slumps: Evidence from Africa. Journal of Development Economics, 52, 121-137. https://doi.org/10.1016/S0304-3878(96)00437-3

[24] Greene, J. and Villanueva, D. (1991) Private Investment in Developing Countries: An Empirical Analysis. Staff Papers (International Monetary Fund), 38, 33-58. https://doi.org/10.2307/3867034

[25] Aschauer, D.A. (1989) Does Public Capital Crowd out Private Capital. Journal of Monetary Economic, 24, 171-188. https://doi.org/10.1016/0304-3932(89)90002-0

[26] Blejer. M.I. and Khan, M.S. (1984) Government Policy and Private Investment in Developing Countries. Staff Papers (International Monetary Fund), 31, 379-403. https://doi.org/10.2307/3866797

[27] Rossiter, R. (2002) Structural Co-Integration Analysis of Private and Public Investment. International Journal of Business and Economics, 1, 59-67.

[28] Chhibber, A. and Wijnbergen, S. (1988) Public Policy and Private Investment in Turkey. PPR Working Paper 120, World Bank, Washington DC.

[29] Oshikoya, T. (1994) Macroeconomic Determinants of Domestic Private Investment in Africa: An Empirical Analysis. Economic Development and Cultural Change, 42, 573-595. https://doi.org/10.1086/452103

[30] Pesaran, M.H., Shin, Y. and Smith, R.J. (2001) Bounds Testing Approaches to the Analysis of Level Relationships. Journal of Applied Econometrics, 16, 289-326.

https://doi.org/10.1002/jae.616

[31] Oteng-Abayie, E.F. and Frimpong, J.M. (2006) Bounds Testing Approach to Cointegration: An Examination of Foreign Direct Investment-Trade and Growth Relationship. American Journal of Applied Sciences, 3, 2079-2085.

https://doi.org/10.3844/ajassp.2006.2079.2085

[32] Narayan, P.K. (2005) The Saving and Investment Nexus for China: Evidence from Cointegration Tests. Applied Economics, 37, 1979-1990. https://doi.org/10.1080/00036840500278103

[33] Ghorbani, M. and Motallebi, M. (2009) Application Pesaran and Shin Method for Estimating Irans' Import Demand Function. Journal of Applied Sciences, 9, 1175 1179. https://doi.org/10.3923/jas.2009.1175.1179

[34] Huybens, E. and Smith, B. (1999) Inflation, Financial Markets and Long-Run Real Activity. Journal of Monetary Economics, 43, 283-315. https://doi.org/10.1016/S0304-3932(98)00060-9

[35] Ajide, K.B. (2013) The Role of Governance on Private Investment in Nigeria: A Preliminary Analysis. Central Bank of Nigeria Economic and Financial Review, 51, 93-119.

[36] Naa-Idar, F., Tutu, D.A. and Frimpong, M.J. (2012) A Time Series Analysis of Determinants of Private Investment in Ghana (1960-2010). Journal of Economics and Sustainable Development, 3, 23-33. 